\title{
Review
}

\section{A Review of Single-Use and Reusable Gowns and Drapes in Health Care}

\author{
William A. Rutala, PhD, MPH; David J. Weber, MD, MPH
}

\begin{abstract}
Gowns and drapes are used widely in healthcare facilities. Gowns have been used to minimize the risk of disease acquisition by healthcare providers, to reduce the risk of patient-to-patient transmission, and during invasive procedures to aid in maintaining a sterile field. Drapes have been used during invasive procedures to maintain the sterility of environmental surfaces, equipment, and patients. This article reviews the use of gowns and drapes in healthcare facilities, including the characteristics, costs, benefits, and barrier effectiveness of single-use and reusable products.

Currently, gowns protect healthcare personnel performing invasive procedures from contact with bloodborne pathogens. Although gowns have been recommended to prevent patient-topatient transmission in certain settings (eg, neonatal intensive care unit) and for certain patients (eg, those infected with vancomycin-
\end{abstract}

resistant enterococci), scientific studies have produced mixed results of their efficacy. While appropriate use of drapes during invasive procedures is recommended widely as an aid in minimizing contamination of the operative field, the efficacy of this practice in reducing surgical-site infections has not been assessed by scientific studies.

Based on an evaluation of the functional requirements, environmental impact, and economics of gowns and drapes, clear superiority of either reusable or single-use gowns and drapes cannot be demonstrated. The selection of particular gowns and drapes by individual healthcare facilities requires an assessment of the facility's requirements, available products, and costs and should be based on the desired characteristics of an ideal gown or drape as defined in this paper (Infect Control Hosp Epidemiol 2001;22:248-257).
Gowns and drapes have been used for more than a century by healthcare professionals. Gowns have been used to minimize the risk of disease acquisition by healthcare providers, to reduce the risk of patient-to-patient transmission, and during invasive procedures to aid in maintaining a sterile surgical or procedure field. Drapes have been used during invasive procedures to maintain sterility of environmental surfaces, equipment, and patients. Modern technology allows gowns and drapes to be constructed of many materials. Healthcare facilities should understand the characteristics of the ideal gown or drape and base their purchase decisions by balancing health and safety concerns with economic, environmental, and comfort issues. ${ }^{1}$

This article addresses important issues regarding gowns and drapes, including a consideration of their uses, characteristics of an ideal gown and drape, benefits, cost, environmental impact, and barrier effectiveness.

\section{USES OF GOWNS AND DRAPES IN HEALTH CARE}

Gowns are used widely in healthcare facilities as part of personal protective equipment to minimize the passage of microbes to surgical patients and to minimize exposure of healthcare providers to infectious agents, especially bloodborne pathogens such as human immunodeficiency virus (HIV), hepatitis B virus, and hepatitis $C$ virus. Drapes are used on patients during invasive procedures to eliminate or minimize the passage of microorganisms from nonsterile to sterile areas, thereby reducing the risk of nosocomial infection.

Healthcare providers are at risk for acquiring infection during patient-care activities, especially bloodborne pathogens during invasive procedures. The risks of acquisition of hepatitis $\mathrm{B},{ }^{2,3}$ hepatitis $\mathrm{C}_{4}{ }^{4}$ and $\mathrm{HIV}^{5,6}$ have been well documented. All three pathogens can be acquired via contact of contaminated body fluids with nonintact skin or

From the Division of Infectious Diseases, University of North Carolina (UNC) School of Medicine, and the Department of Hospital Epidemiology, UNC Health Care System, Chapel Hill, North Carolina.

Address reprint requests to William A. Rutala, PhD, MPH, 547 Burnett-Womack Bldg, CB \#7030, UNC School of Medicine, Chapel Hill, NC 28599-7030.

This paper was supported, in part, by an educational grant from INDA, Association of Nonwoven Fabrics Industry

99-OA-214. Rutala WA, Weber DJ. A review of single-use and reusable gowns and drapes in health care. Infect Control Hosp Epidemiol 2001;22:248-257. 
mucous membranes. Because of these risks, the Occupational Safety and Health Administration (OSHA) promulgated a rule in 1991 to minimize healthcare workers' risks of acquiring bloodborne pathogens. ${ }^{7}$ This rule required that employers provide healthcare workers with appropriate personal protective equipment (PPE). PPE is defined as specialized clothing or equipment for protection against pathogens. The rule lists examples such as gowns, laboratory coats, eye protection, masks, face shields, and gloves. The OSHA rule allows the employer and employee to select the PPE based on the type of exposure and the quantity or amount of body fluids that may be encountered during the performance of the task or procedure. The rule directs that blood or other potentially contaminated body fluids must not reach the employee's work clothes or street clothes, undergarments, skin, eyes, mouth, or other mucous membranes. This protection must last for the expected duration of the task or procedure. The type of PPE required depends on the following three factors: (1) the condition of exposure, which includes the part at risk (eg, face, legs, hands) and the type of the exposure (eg, pressure, fluids, droplets, aerosols); (2) the amount of blood or body fluid exposure (ie, a few drops to large volumes of liquid); and (3) the duration of likely exposure (ie, short exposure, such as starting an intravenous line, or long exposure, such as cardiothoracic surgery).

Nosocomial infections result in substantial morbidity and mortality. The Centers for Disease Control and Prevention (CDC) has estimated that nosocomial infections cause 19,027 deaths and contribute to an additional 58,092 deaths per year. Surgical-site infections (SSIs) have been estimated to cause 3,251 deaths directly and to contribute to 9,726 deaths. ${ }^{8}$ Since the incidence of SSIs in the lowest-risk category of procedures is approximately $1 \%$ and an estimated 27 million surgical procedures are performed each year, more than 270,000 SSIs are likely to occur each year. Multiple strategies have been recommended to reduce the incidence of SSIs, including the proper use of drapes to cover tables, equipment, and the patient, so as to create a sterile field during an invasive procedure. ${ }^{1}$ Drapes most commonly are used during surgery, but they also are used for a variety of other invasive procedures, including cardiac catheterization, lumbar puncture, and placement of arterial or central venous access devices. Drapes are recommended by the CDC to reduce SSIs. ${ }^{9}$ Drapes also are recommended to prevent bloodstream infections during intravascular line insertion. ${ }^{10}$

More recently, gowns have been evaluated as a means to reduce patient-to-patient transmission of resistant pathogens such as methicillin-resistant Staphylococcus aureus (MRSA) and vancomycin-resistant Enterococcus (VRE; see "Benefits" below).

\section{CHARACTERISTICS OF THE IDEAL GOWN OR DRAPE}

The characteristics of an ideal gown or drape have been well defined in the literature but not previously summarized (Table 1).111-15 Each of these characteristics may be measured by one or more "standardized" tests. ${ }^{11}$ These standardized tests have been developed by several organizations, including the American Society for Testing and Materials (ASTM; eg, ASTM F-1670, ASTM F-1671), the American Association of Textile Colorists and Chemists, the Health Industry Manufacturers Association, and the National Fire Prevention Association. Although a variety of tests have been used to compare barrier qualities of fabrics, there is controversy ${ }^{16,17}$ about which test procedure most closely mimics actual conditions found in the surgical environment. Current tests allow a broad categorization of gowns, based on increasing protection from liquid penetration: resistant (ie, resists penetration of liquids but will allow penetration with pressure), repellent (ie, resistance to wetting by a liquid), or impervious (ie, liquid-proof, prevents the penetration of liquids and microorganisms).

For reusable products, one must consider not only the characteristics of the purchased items but also the characteristics of the laundered products. Maintaining manufacturers' specifications is easier for single-use items compared with reusable products.

\section{AVAILABLE GOWNS AND DRAPES}

Surgical gowns and drapes are fabricated from either multiple- or single-use materials. These two basic types of products each have advantages and disadvantages. In addition, within each of these two broad categories, there is considerable variation in design and performance characteristics which reflects the necessary trade-offs in economy, comfort, and degree of protection required for particular surgical procedures. ${ }^{12}$

\section{Traditional Reusable Materials}

From the late 19th century to the 1970s, hospital sheeting used cotton muslin as the primary fabric. During this era, three fabrics were commonly used. All-cotton muslin (140thread-count muslin) is a loosely woven fabric that is soft, absorbent, drapeable, and extremely porous. Since it is readily permeable, this material does not possess any liquidresistance capability. Furthermore, it tends to abrade easily and generate lint. Blended sheeting (180-thread-count percale) consists of a polyester and cotton blended sheeting that has permanent press qualities but otherwise exhibits performance similar to muslin. Finally, T280 barrier (175- to $280-$ thread-count), a tightly woven cotton or polyester-and-cotton blended fabric, was the first reusable fabric with a waterrepellent chemical finish. However, resistance to liquid penetration diminishes with repeated wash cycles. ${ }^{12}$

In the 1980s, new surgical textiles with improved, multiple-use protective qualities were developed. Advances in these materials included more consistent barrier properties, reduced flammability, low lint generation, and extended durability. Two broad groups of products encompass all the known varieties currently available. The first is polyester sheeting, which consists of a tightly woven fabric made of continuousfilament synthetic yarn that is chemically finished. The second includes composite materials, combinations of woven or knitted fabrics engineered to obtain enhanced performance characteristics by laminating or coating them with various 
TABLE 1

Characteristics of an IDEAL Gown or Drape

\begin{tabular}{|c|c|c|}
\hline Characteristic & Gown or Drape & Goal \\
\hline Barrier effectiveness & Both & $\begin{array}{l}\text { Ability to prevent penetration of contaminated liquids (ie, act as a repellent) and micro- } \\
\text { organisms. For reusable products, ability to maintain complete barrier effectiveness } \\
\text { despite multiple washings. }\end{array}$ \\
\hline Infection benefit & Both & Prevent the greatest number of nosocomial infections. \\
\hline Quality maintenance & Both & $\begin{array}{l}\text { Consistent barrier effectiveness and reliability among all new products and, if used, } \\
\text { among all reused products. }\end{array}$ \\
\hline Functionality & Both & Ability to allow wearer to perform activities without hindrance. \\
\hline Comfort & Gown & $\begin{array}{l}\text { Absence of heat fatigue in wearer, which may increase mistakes, impair performance, } \\
\text { make the worker less efficient, and increase the employee's stress; allows moisture to } \\
\text { evaporate quickly; nonallergenic. }\end{array}$ \\
\hline Cost & Both & $\begin{array}{l}\text { Low total cost, including acquisition cost per unit, storage cost, waste handling, laundry } \\
\text { charges (reusable only), waste-disposal cost, potential liability (cost of gown failure), } \\
\text { loss, and damage (reusable only). }\end{array}$ \\
\hline Tear strength & Drape & $\begin{array}{l}\text { Ability to resist tears, which compromises the sterile field and allows penetration of } \\
\text { microorganisms or liquids. }\end{array}$ \\
\hline Strength & Both & Ability to resist punctures. \\
\hline Available sizes & Both & Multiple sizes available (eg, small through extra large). \\
\hline Sterilizibility & Both & Item must be capable of being sterilized, using standard methods (eg, ethylene oxide). \\
\hline Public image & Both & $\begin{array}{l}\text { Must consider local concerns regarding single-use versus reusable products (eg, landfill } \\
\text { problems, water supply, stained reusable products). }\end{array}$ \\
\hline Drapeability & Drape & Ability to conform to patient or equipment contours smoothly and closely. \\
\hline Linting & Both & $\begin{array}{l}\text { Minimize linting. If linting occurs during a surgical procedure, lint may enter the wound } \\
\text { increasing the risks for nosocomial infection and foreign-body reactions. }\end{array}$ \\
\hline Biocompatibility & Both & Does not chemically irritate skin. \\
\hline Toxicity & Both & Does not contain toxic materials. \\
\hline Flammability & Drape>gown & $\begin{array}{l}\text { Flame-resistant fabrics preferred, especially for surgical drapes (ignition devices present } \\
\text { in the OR include lasers, electro-surgical units, and hot-wire cauteries). However, all } \\
\text { fabrics, including fire-resistant fabrics, will burn in an oxygen-enriched environment. }\end{array}$ \\
\hline Abrasiveness & Both & Does not physically damage skin. \\
\hline Odor & Both & Odor free. \\
\hline Storage requirement & Both & Minimize storage requirement. \\
\hline Procedure sets or surgical packs & Both & $\begin{array}{l}\text { Self-contained procedure sets or surgical packs available, which decrease set-up time (single- } \\
\text { use only). }\end{array}$ \\
\hline Environmental impact & Both & $\begin{array}{l}\text { Reusable: production, water, electricity to heat water, sewer, waste disposal. Single-use: } \\
\text { production, waste disposal (landfill). }\end{array}$ \\
\hline Waste disposal & Both & Adheres to local and state solid-waste rules. Minimize total waste disposal. \\
\hline Laundry risk & Both & $\begin{array}{l}\text { Contaminated drapes and gowns, if not properly managed, may represent a risk to per- } \\
\text { sons transporting or cleaning the contaminated item (reusable only). }\end{array}$ \\
\hline
\end{tabular}

Abbreviation: $O R$, operating room.

types of films that provide increased protection against strikethrough of liquids and microorganisms. ${ }^{12}$

\section{Single-Use Materials}

Single-use surgical gowns and drapes are most commonly constructed of nonwoven materials, alone or in combination with materials that offer increased protection from liquid penetration (eg, plastic films). Nonwoven fabrics are derived from various forms of natural (eg, wood pulp, cotton) and synthetic fibers (eg, polyester, polyolefin) that can be engineered to achieve desired properties by the use of special fiber types, bonding processes, and fabric finishes.
The three most commonly used nonwoven fabrics for surgical gowns and drapes are spunlace, a hydroentangled material often consisting of wood pulp and polyester fibers; spunbond/meltblown/spunbond, a fabric consisting of three thermally or adhesively bonded layers (spunbond provides the strength, meltblown the barrier); and wet-laid, a nonwoven fabric consisting of wood pulp or a blend of polyester and wood-pulp fibers. The fibers are suspended in water to obtain a uniform dispersion and then are separated from the slurry by draining the water through a fine mesh screen. ${ }^{12,13}$ Chemical treatments can be used to improve liquid penetration resistance. 


\section{Reinforcement of Reusable and Single.Use Products}

Both reusable and single-use products are commonly reinforced to enhance or improve their properties and performance. For some surgical gowns and drapes, the barrier properties of one ply (ie, single sheet or layer of fabric) of a material may not be adequate for the particular application; in these cases, additional materials are often added in the form of additional layers of material, coating, reinforcements, or laminates. In addition, reinforcement may be added to improve absorbency and nonslippage or to produce other desirable characteristics. ${ }^{12}$ The following materials are being used in reusable and single-use products: standard (one layer) fabric; reinforced fabric (second layer of fabric used to reinforce base material); zoneimpervious fabric; and impervious fabric.

For many years, gowns made from woven 140-count cotton muslin were the standard fabric. However, liquids and skin-cell fragments that ranged from 5 to $60 \mu \mathrm{m}$ could penetrate the threads of 140-count muslin easily, allowing contaminants to reach the patient. The barrier effectiveness of woven materials has been improved by the development of tighter wovens, liquid-repellent finishes, and new fabrics $(100 \%$ polyester fiber).

Another improvement in the reusable fabric area has been the development of layered fabric with a highly resistant membrane between two layers of fabric. These new reusable materials provide good barrier protection on first use, but maintenance of these barrier properties is dependent on controlling all variables during the reprocessing. Some studies have shown that the barrier capabilities of laundered reusable fabrics are diminished. ${ }^{18}$

Liquid-proof protection is available with polyreinforced, nonwoven, single-use products and with some reusable products that incorporate membranes. For situations when resistant or repellent fabric is appropriate, unreinforced nonwoven and reusable gowns and drapes may be chosen. Highly resistant barriers are available with singleuse products made from nonwoven fabrics reinforced with polyethylene and layered reusables with membranes. Gowns must be selected to provide protection against liquid strike-through for the anticipated pressures and blood loss. Some researchers suggest that, with the exception of head and neck surgery, plastic-film reinforced gowns are recommended for all surgical cases when the anticipated blood loss is $>100 \mathrm{~mL}$ and the duration exceeds 2 hours. For most procedures with less than $100 \mathrm{~mL}$ of blood loss or duration less than 2 hours, reinforced gowns are recommended. Plastic-reinforced gowns are suggested for use during procedures conducted in the abdominal area. ${ }^{19}$

\section{BENEFITS}

Gowns are used widely in the hospital in an attempt to reduce the risk of acquiring or transmitting nosocomial infections. The major uses of gowns are twofold. First, gowns are used in surgery and while performing invasive procedures, both to decrease the transmission of skin flora from the healthcare staff and to protect the staff against contact with potentially infective material, such as blood. Second, gowns are used when caring for patients with certain infectious disease (eg, MRSA, respiratory syncytial virus, and VRE) to aid in preventing cross-transmission. The usefulness of barrier precautions has been reviewed. ${ }^{20}$

\section{Role of Gowns During Surgery in Preventing Nosocomial Wound Infections}

The surgical site is the third most common site of nosocomial infections and accounts for approximately 15\% of all nosocomial infections. The CDC estimated that in 1992 SSIs resulted in a mean additional hospital stay of 7.3 days at a mean cost of $\$ 3,152 .{ }^{8}$ The use of highly resistant gowns and drapes in the operating room has been a standard infection control practice to prevent SSIs, because they act as barriers to bacteria that are shed by the patient or the surgical team members into the open wound during the operation. ${ }^{21}$ The CDC recently published a guideline providing science-based recommendations for prevention strategies to reduce the incidence of SSIs. ${ }^{9}$ This guideline made the following recommendation regarding surgical attire and drapes: "use sterile surgical gowns and drapes that are effective barriers when wet (ie, materials that resist liquid penetration)." This recommendation was ranked as a category $1 B$, strongly recommended for implementation and supported by some experimental, clinical, or epidemiological studies and strong theoretical rationale.

Six prospective studies (Table 2), all but one conducted prior to 1990, have compared the use of nonwoven and woven cotton gown and drape fabric to prevent intraoperative wound infections. ${ }^{21-26}$ All studies were conducted in a prospective fashion. Assignment to reusable versus singleuse gowns and drapes differed among the studies and included random assignment, crossover design, and pre- and postinitiation of a disposable draping system. Some, but not all, studies used personnel who were masked as to the type of gown used for assessing the outcome variable (ie, wound infection). The study by Dr. Garibaldi was relatively small, but the authors used intraoperative wound contamination as their primary outcome measure, which effectively increased the power of the study. ${ }^{21}$ They reported that there was only a $10 \%$ probability that they would have missed a significant difference between single-use and reusable gowns, if such a difference truly existed. Several large studies have reported higher infection rates (relative risk $>2.0$ ) associated with reusable fabrics. ${ }^{22,24,25}$ Dr. Moylan and colleagues reported a logistic model using postoperative infection as the dependent variable and five predictors: type of gown (single-use vs reusable), wound category, length of operation, gender, and antibiotics. ${ }^{24}$ In both this model and the model including interaction terms, use of reusable gowns and drapes was associated with a significantly higher rate of SSIs. These studies stand in contrast to the prospective, randomized, masked study of Dr. Garibaldi and colleagues, which was unable to demonstrate a difference in either SSIs or wound contamination between reusable and single-use gowns and drapes. ${ }^{21}$ Methodological flaws potentially present in these earlier studies included lack of true randomization, inadequate descrip- 


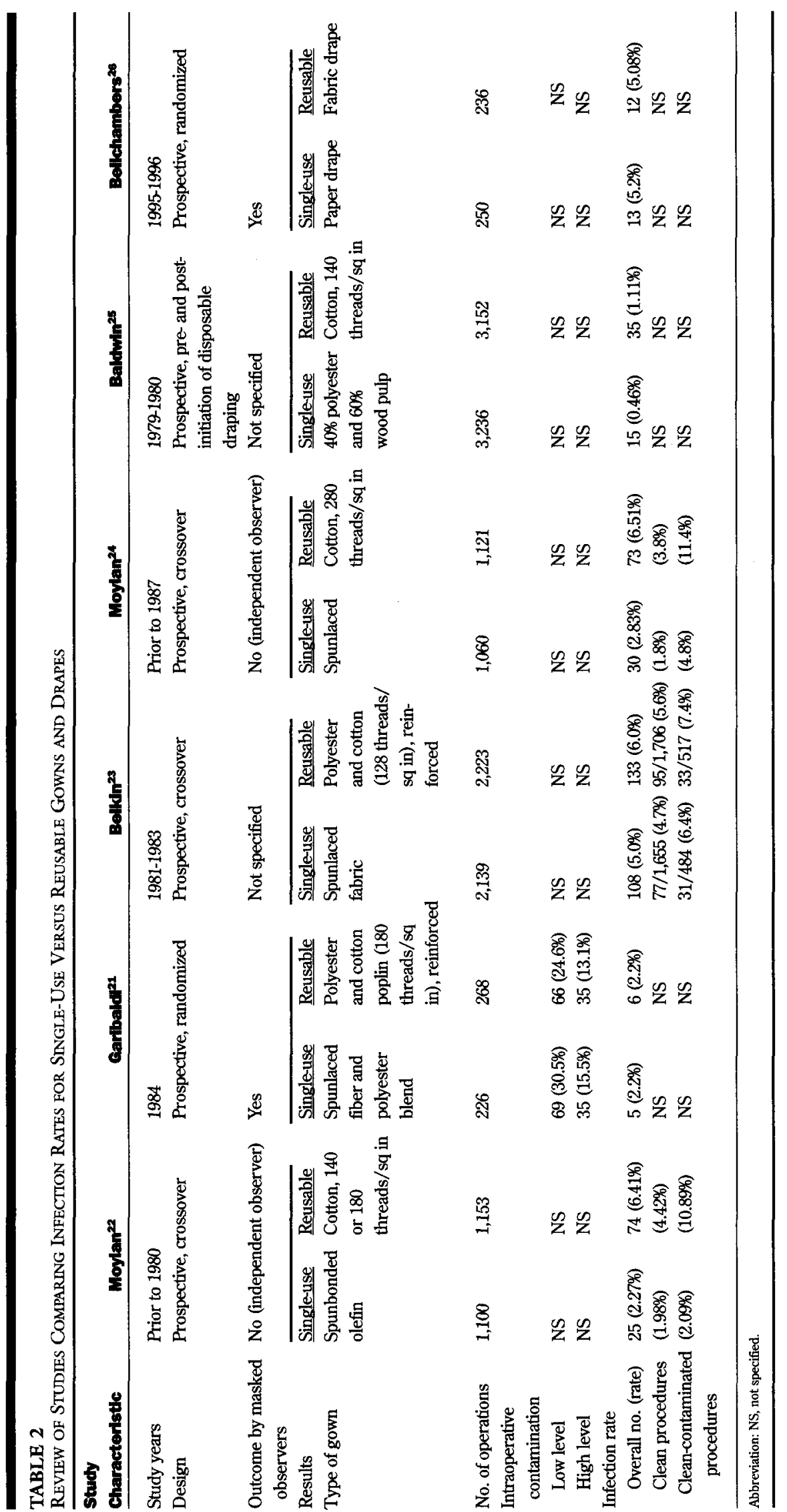


tion of the products tested, failure to account for all patients enrolled, failure to assure that reusable products were used within their life-expectancy, assessment of the primary outcome (ie, SSI) by personnel aware of the subject's intervention, and improper statistical tests.

Recently, Bellchambers and coworkers reported a prospective, randomized, masked study that compared reusable gowns and drapes to single-use items in patients undergoing coronary artery bypass surgery. ${ }^{26}$ No difference in the rates of sternal or leg-wound infections between the groups was noted. A logistic regression of risk factors for sternal wound infection revealed that body mass index $(P=.004)$ and duration of surgery $(P=.02)$, but not type of gown or drape used $(P=.73)$, was associated with sternal wound infections.

Additional studies using currently available single-use gowns and drapes versus reusable gowns are required to assess the clinical impact of single-use versus reusable gowns. Such studies should be prospective and randomized, with independent assessment of outcomes. In addition, other variables such as antimicrobial prophylaxis, surgical scrubs, preoperative showers, and hair-removal methods must be standardized. Such studies should assess other factors, such as healthcare provider comfort, relative costs, other economic measures, and environmental impact.

\section{Role of Gowns in Preventing Cross-Transmission of Nosocomial Pathogens}

The $\mathrm{CDC}$ has provided recommendations for the proper isolation of patients with infectious diseases. ${ }^{27}$ This guideline states that "gowns are worn by personnel during the care of patients infected with epidemiologically important microorganisms to reduce the opportunity for transmission of pathogens from patients or items in their environment to other patients or environments." Gowns should be worn for specified patients known or suspected to be infected or colonized with epidemiologically important microorganisms that can be transmitted by direct contact with the patient (hand or skin-to-skin contact that occurs while performing patient-care activities that require touching the patient's dry skin) or indirect contact (touching) with environmental surfaces or patient-care items in the patient's environment. The guideline states that the gown (a clean, nonsterile gown is adequate) should be worn when entering the room if one anticipates that clothing will have substantial contact with the patient, environmental surfaces, or items in the patient's room, or if the patient is incontinent or has diarrhea, an ileostomy, a colostomy, or wound drainage not contained by a dressing. The gown should be removed prior to leaving the patient's environment. After gown removal, one should ensure that clothing does not contact potentially contaminated environmental surfaces to avoid transfer of microorganisms to other patients or environments. Infections for which gowns are recommended include draining abscesses, adenovirus infection in children, varicella, zoster, congenital rubella, cutaneous diphtheria, certain viral hemorrhagic fevers, Clostridium difficile colitis, multidrugresistant pathogens (eg, VRE, MRSA), pediculosis and other ectoparasites, respiratory syncytial virus (RSV) in children or immunocompromised adults, and major $S$ aureus or streptococcal skin or wound infections. The guideline does not specify what types of gowns should be worn. It also notes that adequate data regarding the efficacy of gowns to prevent cross-transmission are not available.

Gowns or cover gowns have been used for years in hospital newborn units in the belief that they reduce crosstransmission. Studies, including those that have used a randomized design, have demonstrated no benefit to the routine use of cover gowns on postpartum units for healthy full-term infants. ${ }^{28-31}$ Specifically, the incidence of nasal and umbilical colonization with $S$ aureus is not altered by the use of cover gowns. ${ }^{30,31}$

As in newborn units, cover gowns have been widely used in neonatal intensive care units. ${ }^{32}$ Multiple prospective studies have failed to demonstrate that the routine use of cover gowns in this setting decreased bacterial colonization of the infants, overall nosocomial infection rates, or the incidence of intravenous catheter colonization. ${ }^{33-35}$ However, Agbayani and colleagues reported a randomized trial that found that necrotizing enterocolitis occurred more frequently during a modified gowning period than in the gowning period, but were unable to show any consistent difference in colonization, mortality, or infection rates. ${ }^{36}$ Klein and coworkers also reported a reduction in nosocomial infections during pediatric intensive care when protective isolation (which included protective, high-barrier gowns and gloves) was used..$^{37}$

Respiratory syncytial virus represents a serious nosocomial hazard, especially for infants with cardiorespiratory diseases or immunodeficiency states. The virus is spread by close contact with infected secretions, by large-particle aerosols, and by fomites. Small-particle aerosols do not seem to be a major route of transmission. Hospital personnel are thought to be the main vector, transmitting the virus on contaminated hands and even becoming infected themselves by self-inoculation of mucous membranes. Control measures have included hand washing, gloves, gowns, cohorting RSVinfected patients, face masks, and eye-nose goggles. Compliance with both glove and gown use has been demonstrated to reduce the rate of nosocomial RSV infection among children. ${ }^{38}$ A later prospective study demonstrated that the combination of cohort nursing and glove and gown use decreased the risk of RSV transmission but that the use of gowns and gloves alone or cohort nursing alone failed to produce a significant reduction in cross-transmission. ${ }^{39}$

The incidence of nosocomial infections due to MRSA and VRE has dramatically increased in recent years. Control of VRE outbreaks has been achieved by instituting multiple infection control interventions, including the use of disposable gowns when entering the rooms of patients with known or suspected colonization. ${ }^{40,41}$ However, a controlled clinical trial failed to demonstrate that the universal use of gloves and gowns was superior to the universal use of gloves alone in preventing rectal colonization by VRE patients in a medical intensive care unit. ${ }^{42}$ It has been suggested that the failure to demonstrate that gown use 
reduced VRE cross-transmission in this study may have been due to the lack of heavy environmental contamination. ${ }^{43}$ Further studies are needed to determine when the routine use of gowns by personnel provides added protection against the spread of VRE.

\section{ENVIRONMENTAL IMPACT OF GOWNS AND DRAPES}

Both single-use and reusable gowns and drapes have an environmental impact. The environmental impact has been evaluated in an independent report prepared by Arthur D. Little and commissioned by Johnson \& Johnson. ${ }^{44}$ The Little report developed a product life-cycle inventory that allowed comparison of the environmental impact of single-use versus reusable gowns and drapes. The life cycle included resource inputs (energy, water, raw materials); life-cycle stages (raw material acquisition, manufacturing, transportation, use/reuse/maintenance, and waste management); and environmental outputs (water pollutants, air pollutants, solid and hazardous wastes). An analysis of the inventory results showed that neither the single-use nor the reusable products studied were clearly superior from an environmental standpoint. The single-use products consume more raw materials and energy and generate more solid waste than the reusable products. Most of the air emissions (nitrogen oxides, sulfur oxides, and particulates) from manufacture and transport of both types of products result from energy production; hence, the singleuse products produce more energy-related air emissions. These types of air emissions are associated with the air pollution resulting in acid rain. The reusable products consume substantially more water and produce more water pollution. They also generate more volatile organic compounds as air emissions. Volatile organic compound emissions generally are associated with smog levels in the atmosphere. As the Little report notes, it is difficult to place judgment on which types of environmental burdens are more important or damaging to the ecology. ${ }^{44}$

Currently, approximately $80 \%$ of hospitals in the United States have chosen to use single-use gowns. The cost of disposal will be determined, in part, by whether blood-contaminated gowns and drapes constitute "regulated medical wastes" that would require additional and more costly methods of disposal. Whether blood-contaminated gowns and drapes are considered regulated medical waste varies among the different states. In states that do not classify blood-contaminated gowns or drapes as regulated medical waste (eg, North Carolina), it is crucial for healthcare facilities to segregate these items separately from regulated medical wastes to achieve cost savings. However, neither the CDC nor the Environmental Protection Agency provide detailed guidance on whether blood-contaminated gowns and drapes should be considered regulated medical waste.

Overall, hospital waste accounts for $2 \%$ of national municipal wastes. Gowns and drapes contribute approximately $2 \%$ of all hospital waste. Thus, gowns and drapes constitute approximately $0.04 \%$ of all municipal wastes. ${ }^{44}$

\section{COSTS ASSOCIATED WITH REUSE}

The Little report commissioned by Johnson \& Johnson also addressed the economic impact of reusable versus single-use gowns and drapes. This economic analysis considered five cost components: direct costs, drape set-up and changing costs, laundering and reprocessing costs, storage and inventory costs, and disposal costs. For single-use items, direct purchase cost was the most important factor (approximately 90\% of total costs); factors that had an impact on costs of reusable items included the number of reuses, laundering and reprocessing costs (75\%-95\% of total cost), and number of drapes used per procedure. Interestingly, disposal costs for single-use items averaged only $4 \%$ to $5 \%$ of the total costs. Applying this analysis (1991 dollars) to an average single abdominal operation revealed that the total cost for drapes was $\$ 18$ and for gowns was $\$ 10$, with similar cost whether single-use or reusable items were used. ${ }^{44}$

An important factor to consider in cost estimates of reusable gowns is the standard allowance for loss and damage, which often runs approximately $2 \%$. Reusable gowns and drapes may be discarded improperly. Operating room gowns may be removed from the healthcare facility for personal use. The approximate cost of a single-use gown is $\$ 3$ to $\$ 7$, whereas the approximate cost of a reusable reinforced gown is $\leqslant \$ 60 .{ }^{45}$ While some manufacturers predict 75 uses, a hospital's loss, damage (tears, holes), and resistance to blood and viral penetration for 75 launderings or sterilizations may drastically reduce the garment's life span and increase the cost per procedure. A loss rate of $2 \%$ may not seem important, but it will have a substantial impact on the life of the product. For example, a reusable gown with an engineered life of 80 uses in an environment with a $2 \%$ loss or damage rate will have an actual life of only 41 uses (ie, about a 50\% shortened life expectancy).

The actual costs associated with disposable versus reusable scrub suits and gowns in the operating room have been evaluated. Comparing two hospitals, DiGiacomo and colleagues concluded that reusable scrub suits and gowns would result in cost savings in excess of $\$ 100,000$ (1990 dollars) compared to using disposables. ${ }^{46}$ However, single-use scrub suits have not been proposed, and the inclusion of scrub suits skews the data in favor of reusables. In contrast, Moylan ${ }^{24}$ (Table 3) and Murphy ${ }^{47}$ showed lower costs with the use of disposable gowns and drape systems. A costeffectiveness analysis of current reusable versus disposable products should be undertaken using accepted costeffectiveness analysis methodologies.

\section{BARRIER EFFECTIVENESS OF GOWNS AND DRAPES}

Multiple difficulties have been described in the literature regarding the evaluation of the barrier effectiveness of surgical gowns. First, surgical gowns are used for two main purposes: to minimize contamination of the operating room environment by microbial skin flora of participating healthcare workers and to prevent skin or clothing contact by the healthcare team with potentially infective patient material, especially bloodborne pathogens (eg, HIV, hepati- 
TABLE 3

Comparative Annual Costs for Disposable Versus Reusable Gowns and Drapes

\begin{tabular}{|c|c|c|c|}
\hline & $\begin{array}{c}\text { Community } \\
\text { Hospltal }\end{array}$ & $\begin{array}{c}\text { Unlversity } \\
\text { Hospltal }\end{array}$ & $\begin{array}{c}\text { Metropolitan } \\
\text { Hospital }\end{array}$ \\
\hline Annual no. of procedures & 13,100 & 10,924 & 7,334 \\
\hline \multicolumn{4}{|l|}{ Cotton gowns and drapes, $\$$} \\
\hline Laundry costs & 234,400 & 150,120 & 73,162 \\
\hline Direct & 154,100 & 142,000 & 17,532 \\
\hline Indirect & 80,300 & 8,120 & 55,630 \\
\hline Handling costs & 94,100 & 126,896 & 4,550 \\
\hline Purchase costs & 23,000 & 239,320 & 6,913 \\
\hline Other costs & 17,200 & 14,062 & 52,038 \\
\hline Total & 368,700 & 530,398 & 136,663 \\
\hline Cost/procedure & 28.14 & 48.56 & 18.63 \\
\hline \multicolumn{4}{|c|}{ Disposable gowns and drapes, $\$$} \\
\hline Laundry costs & 80,300 & 0 & 0 \\
\hline Direct & 0 & 0 & 0 \\
\hline Indirect & 80,300 & 0 & 0 \\
\hline Handling costs & 7,500 & 0 & 0 \\
\hline Purchase costs & 243,400 & 332,273 & 112,283 \\
\hline Other costs & 6,500 & 0 & 0 \\
\hline Total & 337,700 & 332,273 & 112,283 \\
\hline Cost/procedure & 25.78 & 30.41 & 15.30 \\
\hline
\end{tabular}

Adapted from Moylan JA, et al. ${ }^{24}$

tis B virus). Hence, multiple tests to evaluate barrier effectiveness are required. Second, despite the publication of standardized methods for determining the barrier effectiveness of gowns, universal acceptance of these standardized tests does not exist. Most methods rely on a soak-through of liquids. Third, viral penetration of gowns may occur in the absence of obvious soak-through. Fourth, laboratory testing may not mimic actual in-use testing. Specifically, certain areas of the body are subject to stress and pressure, resulting in increased permeability. Finally, the multitude of products and changes in product design makes generalizations regarding comparative effectiveness difficult.

Multiple test methodologies for assessing the barrier effectiveness of gowns and drapes have been described. These can be divided into tests of fabric characteristics (eg, composition, thickness, air permeability, and water-vapor transmission rate); liquid-barrier properties (eg, mason jar test, penetration of liquids upon impact, hydrostatic pressure tests); and penetration by microorganisms, which may be aerosolized or contained in liquid. Tests of liquid penetration may use a variety of liquids, including water, synthetic blood, or human blood. Some tests are qualitative, providing only a positive or negative result, whereas others provide quantitative results.

The viral penetration of surgical gowns by HIV has been compared to the soak-through point by multiple investigators. ${ }^{48,49}$ Both studies reported that HIV could penetrate some surgical-gown materials in common use at the time of the studies. Further, HIV penetration was sometimes noted in the absence of visible soak-through.
Because certain areas of the body are subject to stress and pressure resulting in increased permeability, Beck and Collette ${ }^{50}$ and Bernard and Beck ${ }^{51}$ have suggested that gowns should be tested both in the laboratory setting and under conditions of use. Simulated surgical movements (ie, leaning, reaching, arm resting) have been found to develop less than 2 psi pressure. ${ }^{45}$ Using a 32 -sensor mat placed in the abdominal area of a surgeon during operative procedures, Smith and colleagues demonstrated that pressure contacts were frequent, generally less than $2.9 \mathrm{psi}$, and lasted less than 15 seconds. ${ }^{52}$ Liquid strike-through has been demonstrated in laboratory tests to be both pressureand time-dependent. ${ }^{45,53}$ The importance of pressure in leading to strike-through has been demonstrated by evaluating gowns after clinical use in surgical procedures. An evaluation of blood strike-through during 234 surgical procedures revealed that strike-through was related to the extent of contamination on the outside of the gown and was heavy in areas of the gown subjected to stress or pressure (ie, chest, forearm, abdomen). ${ }^{54}$ Pissiotis and coworkers observed the following rates of strike-through: reusable gowns, 90\%; disposable single-layer gowns, 11\%; and disposable reinforced gowns, $3 \% .{ }^{55}$ The areas most vulnerable to strike-through were the cuff, forearm, thigh, chest, and abdomen. Ahmad and colleagues demonstrated the following failure rates of gowns to prevent blood strike-through in obstetrical procedures: single-layer nonwoven fabric, $55.8 \%$; reinforced fabric, $26.7 \%$; reinforced fabric with highly resistant fabric in chest and forearms, $21.1 \%$; and full length with impervious front panel and forearms and ther- 
mally sealed side seams, $16.7 \% .^{56}$ Prolonged contact of gowns with blood may result in increased permeability when external pressure is applied. ${ }^{57} \mathrm{~A}$ recent study of multiple hospitals in Germany demonstrated that deficiencies could be observed in the processed items (eg, 58\% had holes in one or more individual items).$^{58}$

Bearing in mind the above-mentioned difficulties in assessing the comparative barrier effectiveness of gowns, recent studies allow the following generalizations. ${ }^{45,49,53,5962}$ Fabric characteristics, such as construction, repellency, and pore size, contribute to gown performance. Laminates or polypropylene-treated gowns (eg, 97\%-100\% polypropylene, spunbond/meltblown/spunbond laminates) provide the greatest protection against blood strike-through and bacterial penetration. Gowns composed of a single layer of nonwoven fabric provide the next greatest effectiveness. Gowns composed of $100 \%$ woven cotton, used on reusable products, provided the least protection. Individual products may vary greatly, and these conclusions are only generalizations.

The cumulative effect of laundering on the barrier efficacy of reusable cotton gowns has been studied by several investigators. ${ }^{18,53}$ In general, reusable gowns provided less protection than new gowns. ${ }^{18,45,61}$ Leonas reported that reusable gowns with a single layer of fabric demonstrated an increased amount of bacteria transmitted through the fabric after laundering, whereas those reinforced with a second fabric layer did not. ${ }^{18}$ Granzow reported that washed reusable gowns composed of $100 \%$ woven cotton were somewhat more effective in preventing blood strike-through and passage of $S$ aureus than new reusable gowns. ${ }^{53}$ However, Belkin noted that this finding is likely attributable to the apparently loosely woven, readily permeable, $100 \%$ cotton fabric shrinking during the laundry process(es), and the tightening up of the (warp and fill) yarns..$^{63}$

\section{CONCLUSION}

Appropriate gowns are useful to prevent exposure to bloodborne pathogens by healthcare workers. The use of gowns to prevent patient-to-patient transmission of nosocomial pathogens remains controversial, because studies assessing the efficacy of gowns have produced mixed results. The use of drapes in invasive procedures is widely recommended, for theoretical reasons, to minimize microbial contamination of the surgical site, although modern scientific studies have not assessed the efficacy of barrier protection in this setting.

Older studies suggested that single-use gowns and drapes used during surgical procedures were superior to reusable products in preventing SSIs. These studies have limited relevance because of methodological flaws and product improvements. Only limited data are available regarding currently available products. In conclusion, a clear superiority of currently available single-use gowns and drapes versus reusable products has not been demonstrated based on efficacy to prevent infections, environmental impact, or economics. The selection of particular gowns and drapes by individual healthcare facilities requires an assessment of the facility's requirements, avail- able products, and costs, and should be based on the desired characteristics of an ideal gown or drape.

\section{REFERENCES}

1. Manz EA, Edgar BL. Examining draping practices for cost-effectiveness. Surgical Services Management 1998;4:41-47.

2. Weber DJ, Rutala WA. Hepatitis B immunization update. Infect Control Hosp Epidemiol 1989;10:541-546.

3. Mahoney FJ, Stewart K, Hu H, Coleman P, Alter MJ. Progress toward the elimination of hepatitis $B$ virus transmission among health care workers in the United States. Arch Intern Med 1997;157:2601-2605.

4. Centers for Disease Control and Prevention. Recommendations for prevention and control of hepatitis $C$ virus (HCV) infection and HCV-related chronic disease. $M M W R$ 1998;47(RR-19):1-39.

5. Cardo DM, Bell DM. Bloodborne pathogen transmission in health care workers: risks and prevention strategies. Infect Dis Clin North Am 1997;11:331-346.

6. Bell DM. Occupational risk of human immunodeficiency virus infection in healthcare workers: an overview. Am J Med 1997;102(5B):9-15.

7. Occupational Safety and Health Administration. Occupational exposure to bloodborne pathogens: final rule. Fed Regist 1991; 56:235:64175-64182.

8. Emori TG, Gaynes RP. An overview of nosocomial infections, including the role of the microbiology laboratory. Clin Microbiol Rev 1993;6:428-442.

9. Mangram AJ, Horan TC, Pearson ML, Silver LC, Jarvis WR, the Hospital Infection Control Practices Advisory Committee. Guidelines for the prevention of surgical site infection, 1999. Infect Control Hosp Epidemiol 1999;20:247-280.

10. Centers for Disease Control and Prevention. Intravascular devicerelated infections prevention. Fed Regist 1995;60:87:49978-50006.

11. Medical/Surgical Technical Committee, Association of the Nonwoven Fabrics Industry. Guide to Nonwoven Medical Products. New York, NY: Association of the Nonwoven Fabrics Industry; 1984.

12. Technical Information Report, Association for the Advancement of Medical Instrumentation. Selection of Surgical Gowns and Drapes in Health Care Facilities. Arlington, VA: Association for the Advancement of Medical Instrumentation; 1994. TIR No 11-1994.

13. Rainford S, Yannetta I, Hunt G. Surgical gowns. Infect Control Today 1998;1:21-22.

14. Payne DG. The evolving world of surgical attire. Infect Control Steril Technol 1998;4:20-26.

15. Lewis JA, Brown PL. Breaking the comfort barrier in impervious gowns. Surg Services Management 1998;4:29-30,32,35-36,38.

16. Belkin NL. Effect of laundering on the barrier properties of reusable surgical gown fabrics. Am J Infect Control 1999;27:304-305.

17. Brown PL. Defining the clinical relevance of surgical barrier testing. Am J Infect Control 1999;27:305-307.

18. Leonas KK. Effect of laundering on the barrier properties of reusable surgical gown fabrics. Am J Infect Control 1998;26:495-501.

19. Telford GL, Quebbeman EJ. Assessing the risk of blood exposure in the operating room. Am J Infect Control 1993;21:351-356.

20. Goldmann DA. The role of barrier precautions in infection control. $J$ Hosp Infect 1991;18(suppl A):515-523.

21. Garibaldi RA, Maglio S, Lerer T, Becker D, Lyons R. Comparison of nonwoven and woven gown and drape fabric to prevent intraoperative wound contamination and postoperative infection. Am J Surg 1986;152:505-509.

22. Moylan JA, Kennedy BV. The importance of gown and drape barriers in the prevention of wound infection. Surg Gynecol Obstet 1980;151:465-470.

23. Belkin NL. Are "barrier" drapes cost effective? Today's Surg Nurse 1998;20:18-23.

24. Moylan JA, Fitzpatrick KT, Davenport KE. Reducing wound infections: improved gown and drape barrier performance. Arch Sung 1987;122:152-157.

25. Baldwin BC, Fox IL, Russ C. Affect of disposable draping on wound infection rate. $\mathrm{Va} \mathrm{Med} 1981 ; 108: 477$.

26. Bellchambers J, Harris JM, Cullinan P, Gaya H, Pepper JR. A prospective study of wound infection in coronary artery surgery. Eur $J$ Cardiothoracic Surg 1999;15:45-50.

27. Garner JS, the Hospital Infection Control Practices Advisory Committee. Guideline for isolation precautions in hospitals. Infect Control Hosp Epidemiol 1996;17:53-80.

28. Renaud MT. Effects of discontinuing cover gowns on a postpartal ward upon cord colonization of the newborn. JOGN Nurs 1983;12:399-401.

29. Williams CPS, Oliver TK. Nursery routines and staphylococcal colonization of the newborn. Pediatrics 1969;44:640-646.

30. Birenbaum HJ, Glorioso L, Rosenberger C, Arshad C, Edwards K. Gowning on a postpartum ward fails to decrease colonization in the newborn infant. Am J Dis Child 1990;144:1031-1033. 
31. Rush J, Fiorino-Chiovitti R, Kaufman $\mathrm{K}$, Mitchell A. A randomized controlled trial of a nursery ritual: wearing cover gowns to care for healthy newborns. Birth 1990;17:25-30.

32. Cloney DL, Donowitz LG. Overgown use for infection control in nurseries and neonatal intensive care units. Am J Dis Child 1986;140:680-683.

33. Evans HE, Solomon OA, Baki A. Bacteriologic and clinical evaluation of gowning in a premature nursery. J Pediatr 1971;78:883-886.

34. Donowitz LG. Failure of the overgown to prevent nosocomial infection in a pediatric intensive care unit. Pediatrics 1986;77:35-38.

35. Haque $\mathrm{KN}$, Chagla $\mathrm{AH}$. Do gowns prevent infection in neonatal intensive care units? I Hosp Infect 1989;14:159-162.

36. Agbayani M, Rosenfeld W, Evans H, Salazar D, Jhaveri R, Braun J. Evaluation of modified gowning procedures in a neonatal intensive care unit. Am J Dis Child 1981;135:650-652.

37. Klein BS, Perloff WH, Maki DG. Reduction of nosocomial infection during pediatric intensive care by protective isolation. $N$ Engl J Med 1989;320:1714-1721.

38. Leclair JM, Freeman J, Sullivan BF, Crowley CM, Goldmann DA Prevention of nosocomial respiratory syncytial virus infections through compliance with glove and gown isolation precautions. $N$ Engl J Med 1987;317:329-334.

39. Madge P, Paton JY, McColl JH, Mackie PLK Prospective controlled study of four infection-control procedures to prevent nosocomial infection with respiratory syncytial virus. Lancet 1992;340:1079-1083.

40. Boyce JM, Opal SM, Chow JW, Zervos MJ, Potter-Bynoe G, Sherman $\mathrm{CB}$, et al. Outbreak of multidrug-resistant Enterococcus faecium with transferable vanB class vancomycin resistance. I Clin Microbiol 1994-32:1148-1153.

41. Boyce JM, Mermel LA, Zervos MJ, Rice LB, Potter-Bynoe G, Giorgio C, et al. Controlling vancomycin-resistant enterococci. Infect Control Hosp Epidemiol 1995;16:634-637.

42. Slaughter S, Hayden MK, Nathan C, Hu T, Rice T, Van Voorhis J, et al. A comparison of the effect of universal use of gloves and gowns with that of glove use alone on acquisition of vancomycin-resistant enterococci in a medical intensive care unit. Ann Intern Med 1996;5:448-456.

43. Boyce JM. Vancomycin-resistant Enterococcus: detection, epidemiology, and control measures. Infect Dis Clin North Am 1997;11:367-384.

44. McDowell JW. An environmental, economic, and health comparison of single-use and reusable drapes and gowns. Asepsis 1993:1-15.

45. Smith JW, Nichols RL. Barrier efficiency of surgical gowns: are we really protected from our patients' pathogens? Arch Surg 1991;126:756-763.

46. DiGiacomo JC, Odom JW, Ritota PC, Swan KG. Cost containment in the operating room: use of reusable versus disposable clothing. Am Surg 1992;58:654-656
47. Murphy $L$. Cost/benefit study of reusable and disposable OR draping materials. J Health Mater Manage 1993;11:44-48.

48. Tyler DS, Lyerly HK, Nastala CL, Shadduck PP, Fitzpatrick KT, Langlois $\mathrm{AJ}$, et al. Barrier protection against the human immunodeficiency virus. Curr Surg 1989;46:301-304.

49. Shadduck PP, Tyler DS, Lyerly HK, Sebastian MW, Farnitano C, Fitzpatrick KT, et al. Commercially available surgical gowns do not prevent penetration by HIV-1. Surgical Forum 1990;41:77-80.

50. Beck WC, Collette TS. False faith in the surgeon's gown and surgical drape. Am J Surg 1952;83:125-126.

51. Bernard HR, Beck WC. Operating room barriers-idealism, practicality and the future. Bull Am Coll Surgeons 1975;60:16.

52. Smith JW, Tate WA, Yazdani S, Garcia RY, Muzik AC, Nichols RI. Determination of surgeon-generated gown pressures during various surgical procedures in the operating room. Am $J$ Infect Control 1995;23:237-246

53. Granzow JW, Smith JW, Nichols RL, Waterman RS, Muzik AC Evaluation of the protective value of hospital gowns against blood strikethrough and methicillin-resistant Staphylococcus aureus penetration. Am J Infect Control 1998;26:85-93.

54. Quebbeman EJ, Telford GL, Hubbard S, Wadsworth K, Hardman B, Goodman $\mathrm{H}$, et al. In-use evaluation of surgical gowns. Gynecol Obstet 1992;174:369-375

55. Pissiotis CA, Komborozos V, Papoutsi C, Skrekas G. Factors that influence the effectiveness of surgical gowns in the operating theatre. Eur J Surg 1997; 163:597-604

56. Ahmad FK, Sherman SJ, Hagglund KH. The use and failure rates of protective equipment to prevent blood and bodily fluid contamination in the obstetric health care worker. Obstet Gynecol 1998;92:131-136.

57. Flaherty AL, Wick TM. Prolonged contact with blood alters surgical gown permeability. Am I Infect Control 1993;21:249-256.

58. Werner HP, Feltgen M. Quality of surgical drape and gown materials. Hyg Med 1998;23:9-29.

59. Lovitt SA, Nichols RL, Smith JW, Muzik AC, Pearce PF Isolation gowns: a false sense of security? Am J Infect Control 1992;20:185-191.

60. McCullough EA, Schoenberger LK. Liquid barrier properties of nine surgical gown fabrics. INDA Joumal of Nonwovens Research 1991;3:14-20.

61. McCullough EA. Methods for determining the barrier efficacy of surgical gowns. Am J Infect Control 1993;21:368-374.

62. Leonas KK, Jinkins RS. The relationship of selected fabric characteristics and the barrier effectiveness of surgical gown fabrics. Am I Infect Control 1997;25:16-23.

63. Belkin NL. Evaluating the protective value of hospital gowns. Am J Infect Control 1999;27:17\&-179.

\section{Vancomycin Use and VRE Colonization in Dialysis Patients}

\section{Gina Pugliese, RN, MS Martin S. Favero, PhD}

Vancomycin is widely used with hemodialysis patients as empirical therapy for dialysis-associated infections. To determine the relation of this practice to the generation of vancomycin-resistant enterococcal (VRE) colonization, Atta and coinvestigators from Johns Hopkins in Baltimore, Maryland, conducted a 2-year prospective cohort study. Cultures for VRE were taken from rectal swabs obtained from patients at the start and finish of the study period and during interim hospitalizations.

The results showed that 10 of 124 patients initially grew VRE. Twenty-four of the remaining patients had no followup cultures because of patient death $(62 \%)$, transfer to another dialysis facility
(17\%), patient's refusal $(7 \%)$, and transplantation (4\%), and thus were excluded. The remaining patients $(n=90)$ had a median age of 54.3 years and were $92 \%$ African American and 50\% male. Fiftyeight percent were treated by hemodialysis. They received $403 \mathrm{~g}$ of intravenous vancomycin over 157.2 patient-years of follow-up, $73 \%$ as outpatients.

Sixteen (17.8\%) of 90 patients became colonized with VRE, an incidence rate of one case per 9.8 patient-years of follow-up. None of the 29 patients who did not receive vancomycin developed VRE compared with $26 \%$ of those treated with vancomycin $(P=.001)$. The odds ratio (95\% confidence interval) for the association of outpatient vancomycin $(\mathrm{g} / \mathrm{y})$ with VRE colonization was $1.23(1.05,1.44, P=.008)$. The association remained significant following adjustment in separate logistic regression analyses for relevant demographic, clini- cal, antimicrobial (inpatient vancomycin, oral or intravenous cephalosporins, aminoglycosides, quinolones, or anti-anaerobics), and hospitalization exposures. The unadjusted relative risk of death in patients growing VRE was significantly higher than in those not colonized with VRE $(P=.005)$

The authors concluded that VRE colonization is a relatively common and underrecognized problem among chronic dialysis patients and is strongly and independently associated with the outpatient use of vancomycin, which should be avoided whenever possible.

FROM: Atta MG, Eustace JA, Song $X$, Perl TM, Scheel PJ. Outpatient vancomycin use and vancomycin-resistant enterococcal colonization in maintenance dialysis patients. Kidney Int 2001;59: 718-724. 